\title{
How Do Breast Cancer Patients Present Following COVID-19 Early Peak in a Breast Cancer Center in Turkey?
}

\author{
(D) Aysun Dauti Işıklar , (D) Cem Deniz², (D) Aykut Soyder ${ }^{1}$, (D) Nilgün Güldoğan ${ }^{1}$, (D) Ebru Yılmaz ${ }^{1}$, (D) Gül Başaran ${ }^{1,2}$ \\ ${ }^{1}$ Breast Health Center, Acıbadem Altunizade Hospital, İstanbul, Turkey \\ ${ }^{2}$ Acıbadem University School of Medicine, İstanbul, Turkey
}

\begin{abstract}
Objective: Coronavirus disease 2019 (COVID-19) has placed an unprecedented burden on healthcare systems and restricted resources for non-COVID patients worldwide. Treatment approaches and follow-up plans have been modified to prevent the risk of infection for patients and healthcare workers. Patients prefer to delay or cancel their treatments during the peak period of infection.

Materials and Methods: We retrospectively reviewed the characteristics of patients with breast cancer who were consulted at our outpatient clinic right after early COVID-19 peak in May and June 2020 and compared them with the same period in 2017 to 2019.

Results: The number of patients who consulted at our outpatient medical oncology clinic declined in May and June 2020. This decline was regardless of stage and was larger in May than in June 2020. In general, the distribution of tumor subtypes [luminal, human epidermal growth factor receptor 2 (HER-2) positive, and triple negative] was not different from 2017 to 2020. Less than half of the patients received adjuvant chemotherapy following early COVID-19 peak in May and June 2020. Few patients received chemotherapy for metastatic disease, whereas many metastatic patients received endocrine therapy. None of the consulted new patients had a non-invasive disease. More patients received endocrine therapy than chemotherapy.

Conclusion: The presentation patterns of patients with breast cancer after early COVID-19 peak differed from those during the same period in the last 3 years. The pandemic affected the number of new patients consulted and the way medical oncologists treat their patients.
\end{abstract}

Keywords: Breast cancer, COVID-19, early peak

Cite this article as: Dauti Işıklar A, Deniz C, Soyder A, Güldoğan N, Yılmaz E, Başaran G. How Do Breast Cancer Patients Present Following COVID-19 Early Peak in a Breast Cancer Center in Turkey?. Eur J Breast Health 2021; 17(3): 253-257

\section{Key Points}

- COVID-19 pandemic led to important changes in the breast units of hospitals.

- The number of consulted patients decreased because of early curfew and right after the early peak of pandemic.

- Medical oncologists preferred less toxic treatment modalities more in May and June 2020 than in the last 3 years.

\section{Introduction}

The coronavirus disease 2019 (COVID-19) pandemic has led to practical changes in the management of patients with breast cancer worldwide (1). Multidisciplinary oncology teams modified their treatment decisions with respect to surgical approach, radiotherapy, and optimal systemic therapy to ensure maximal protection from infection based on their regional dynamics (2).

The first documented COVID-19 case in Turkey was reported on March $11^{\text {th }}$ 2020. The peak for active cases was reached in the last week of April 2020 (3). Acibadem Altunizade Hospital is one of the largest hospitals of the Acibadem Healthcare Health Group in Turkey with a capacity of 350 beds. It has a specific unit for the diagnostic and therapeutic management of breast cancer. At the outset of the COVID-19 pandemic, in line with the precautions of Acibadem Hospital, our breast center has adapted to the management of patients with breast cancer and delayed elective operations of elderly and follow-up patients until the end of April. New diagnoses and suspicious relapses were handled as usual. Ongoing chemotherapies continued throughout the pandemic, unless the performance and comorbidities of the patients were not restrictive/ compromising. Endocrine therapy is opted for patients with hormone receptor-positive metastatic breast cancer, whereas oral chemotherapeutic agents are preferred for patients with newly diagnosed metastatic breast cancer or progressed metastatic breast cancer. Breast surgery was delayed 
for patients with early breast cancer if they were endocrine sensitive and can be managed by endocrine therapy until optimal settings are available. Following the peak, curfew restrictions for people over 65 years old, those with chronic illnesses, and young people under 20 years old were eased by government at the beginning of May 2020. Therefore, a number of patients who need oncological care and those who were referred for oncological therapy started to come to the medical centers. Surgery for early breast cancer started safely with precautions, and outpatient follow-ups commenced for patients with high risk of recurrence at oncology clinics in Istanbul. Patients with undiagnosed breast lumps during the peak or patients with biopsyproven breast cancer right after the early peak sought radiological imaging and surgical attention in May and June 2020.

The present study aimed to characterize new patients who were evaluated at our center right after the early peak of COVID-19 infection in May and June 2020. Past patient records were analyzed to characterize new patients who were admitted in May and June 20172019. This study focused on the presentation of new cases in terms of stage, tumor subtype, age, and preferred therapy.

\section{Materials and Methods}

We retrospectively reviewed the records of patients who were consulted at our outpatient clinic and noted their stage at presentation, tumor subtype, and recommended therapy right after early peak of COVID-19 in May and June 2020. We also reviewed the same parameters for the patients who presented at the same period in 2017-2019. This cross-sectional retrospective study was approved by the institutional review board at Altunizade Acibadem Hospital Hospital (no: 755, date: 01.09.2020).

\section{Results}

The number of patients consulted at our outpatient medical oncology clinic declined. Figure 1 shows our patient profile based on the disease stage in 2017-2020. Fewer patients with early disease and metastatic disease were consulted in May and June 2020 than in the same months of 2017-2019. The number of patients who needed neoadjuvant therapy was similar between 2019 and 2020, greater than that in 2017 and less than that in 2018 .

We have consulted 428, 702, 610, and 521 patients (patients on chemotherapy, new patients, and follow-up patients were all included) in May and June of 2017, 2018, 2019, and 2020, respectively, at our center (Table 1). Among 521 patients consulted in May and June 2020, 36 were new cases. Median age was 50 and similar to that of the last 3 years. Eighteen out of 36 patients have been recently operated for early breast cancer during the peak months of COVID-19 infection. One patient who underwent breast-conserving surgery 3 years ago presented with ipsilateral local relapse, and mastectomy was recommended. Thus, these patients were recorded as having early-stage disease. Of the 18 patients who underwent breast surgery, 11 received breast-conserving surgery, one mastectomy, two bilateral subcutaneous mastectomy, and four subcutaneous mastectomy. Among early-stage patients, 14 had node-negative and three had node-positive disease.

Neoadjuvant therapy was recommended for 11 patients, and five patients had metastatic disease at the time of admission. Among metastatic presentations, one patient had de novo disease, one patient relapsed while on adjuvant endocrine therapy, one patient had progressive disease while on therapy for metastatic breast cancer, and 2 patients were consulted for a second opinion. Three of the metastatic patients had visceral metastases. Table 2 shows patient and treatment characteristics in May and June 2017-2020.

In general, the distribution of tumor subtypes by immunohistochemistry as luminal, HER-2 positive, and triple negative showed no significant difference from 2017 to 2020 (Figure 2). Table 3 shows the distribution of tumor subtypes for patients who received adjuvant and neoadjuvant therapy and for metastatic patients.

The recommended adjuvant therapy for patients who had breast surgery in May and June 2017, 2018, 2019, and 2020 is shown in Figure 3. Two thirds of the patients received adjuvant chemotherapy in May and June 2017-2019. Less than half of the patients received adjuvant chemotherapy following early COVID-19 peak in May and June 2020. Few patients received chemotherapy for metastatic disease, and many metastatic patients received endocrine therapy (Figure 4). Two patients received neoadjuvant endocrine therapy in 2019

\section{Stage of breast cancer}

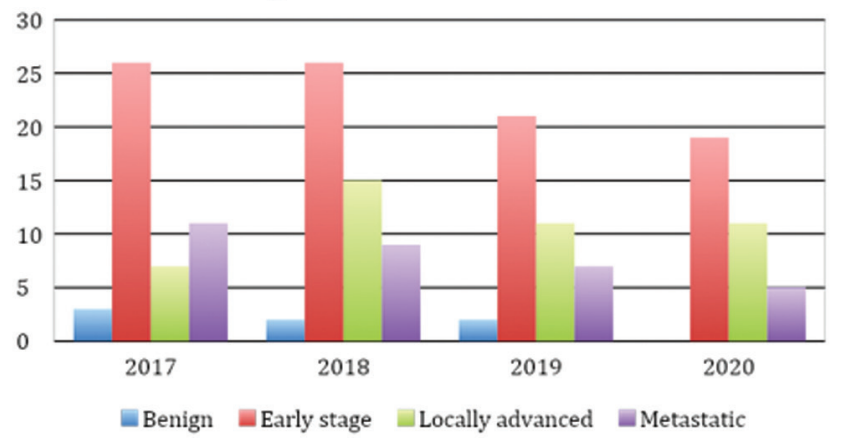

Figure 1. Patient profile based on the disease stage in May and June 2017-2020

Table 1. Patient consulted in May-June between 2017-2020

\begin{tabular}{|c|c|c|c|c|c|c|c|c|}
\hline \multirow[b]{2}{*}{ Patient consulted ( $n$ ) } & \multicolumn{2}{|c|}{2017} & \multicolumn{2}{|c|}{2018} & \multicolumn{2}{|c|}{2019} & \multicolumn{2}{|c|}{2020} \\
\hline & May & June & May & June & May & June & May & June \\
\hline New patients & 24 & 23 & 35 & 18 & 32 & 11 & 9 & 27 \\
\hline Follow-up & 105 & 76 & 197 & 119 & 144 & 136 & 59 & 180 \\
\hline On IV therapy & 102 & 98 & 177 & 156 & 168 & 119 & 124 & 120 \\
\hline
\end{tabular}


and 2020, and none of the patients received neoadjuvant endocrine therapy in 2017 and 2018 (Figure 5). Two patients who received neoadjuvant therapy in 2020 were elderly patients aged 87 and 72 years old. Similarly, the two other patients who received neoadjuvant endocrine therapy in 2019 were elderly patients aged 95 and 72 years old.

\section{Tumor subtypes by IHC between 2017-2020}

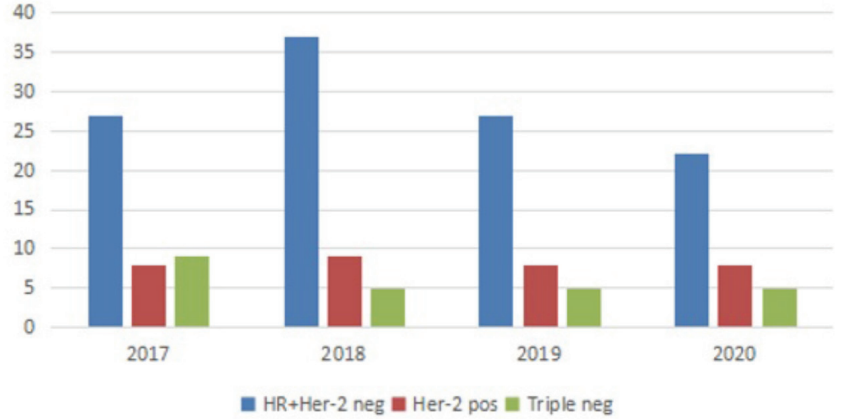

Figure 2. Tumor subtype in May-June 2017-2020

IHC: Immunochistochemistry; HR: Hormon receptor; HER2: Human epidermal growth factor receptor 2

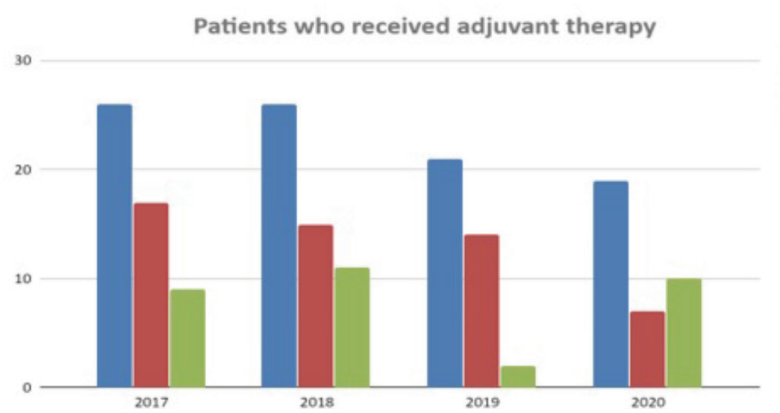

Figure 3. Recommended adjuvant therapy

CT: Chemotheraphy; ET: Endocrintheraphy; n: Number

\section{Discussion and Conclusion}

The COVID-19 pandemic has dramatically changed inpatient and outpatient care in oncology clinics as in other healthcare workers. All preventive and follow outpatient visits are postponed to decrease the risk of transmitting the virus to either patients or healthcare workers. Oncological emergencies and new diagnoses requiring urgent therapy were continued. Telemedicine visits were organized for elderly patients or patients with comorbidities. Patients with cancer are susceptible to infection because of their systemic immunosuppressive state caused by malignancy and anticancer treatments, such as

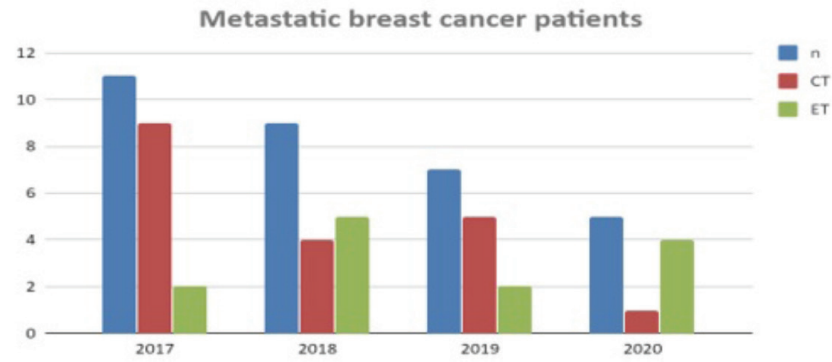

Figure 4. Patients with metastatic breast cancer CT: Chemotheraphy; ET: Endocrintheraphy; n: Number

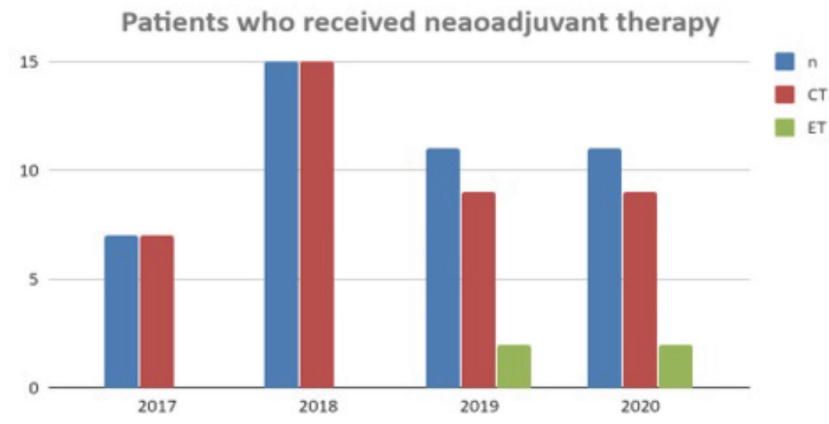

Figure 5. Patients who received neoadjuvant therapy CT: Chemotheraphy; ET: Endocrintheraphy; n: Number

Table 2. Patient characteristics in May and June 2017-2020

\begin{tabular}{|c|c|c|c|c|c|}
\hline \multicolumn{2}{|l|}{ Period } & $\begin{array}{c}\text { May-June } \\
2017\end{array}$ & $\begin{array}{c}\text { May-June } \\
2018\end{array}$ & $\begin{array}{c}\text { May-June } \\
2019\end{array}$ & $\begin{array}{c}\text { May-June } \\
2020\end{array}$ \\
\hline \multicolumn{2}{|l|}{ Number } & 47 & 53 & 42 & 36 \\
\hline \multicolumn{2}{|l|}{ Median age } & $48(26-83)$ & $45(26-85)$ & 49 (33-95) & $50(27-82)$ \\
\hline \multicolumn{2}{|l|}{ DCIS or LCIS } & 3 & 2 & 2 & 0 \\
\hline \multicolumn{2}{|c|}{ Received adjuvant therapy following breast surgery } & 26 & 26 & 21 & 19 \\
\hline \multicolumn{2}{|c|}{ Received neoadjuvant therapy } & 7 & 15 & 11 & 11 \\
\hline \multicolumn{2}{|c|}{ Metastatic (total) } & 11 & 9 & 7 & 5 \\
\hline \multicolumn{2}{|l|}{ De novo } & 6 & 2 & 2 & 1 \\
\hline \multicolumn{2}{|l|}{ Relapsed } & 2 & 1 & 1 & 1 \\
\hline \multicolumn{2}{|l|}{ Second opinion } & 1 & 6 & 2 & 2 \\
\hline \multicolumn{2}{|c|}{ PD on therapy for MBC } & 2 & 0 & 2 & 1 \\
\hline \multirow{2}{*}{ Metastatic site } & Visceral & 7 & 7 & 3 & 3 \\
\hline & Non-visceral & 4 & 2 & 0 & 3 \\
\hline
\end{tabular}


Table 3. Tumor subtype for patients who received adjuvant, neoadjuvant therapy, and for metastatic patients

\begin{tabular}{|c|c|c|c|c|c|}
\hline Period & $\begin{array}{l}\text { Tumor } \\
\text { subtype }\end{array}$ & $\begin{array}{c}\text { May-June } \\
2017\end{array}$ & $\begin{array}{c}\text { May-June } \\
2018\end{array}$ & $\begin{array}{c}\text { May-June } \\
2019\end{array}$ & $\begin{array}{c}\text { May-June } \\
2020\end{array}$ \\
\hline \multirow{3}{*}{ Operated and received adjuvant therapy } & $\begin{array}{c}\text { HR-positive } \\
\text { HER-2 negative }\end{array}$ & 16 & 20 & 15 & 12 \\
\hline & HER-2 positive & 6 & 4 & 4 & 4 \\
\hline & Triple-negative & 4 & 3 & 3 & 3 \\
\hline \multirow{3}{*}{ Received neoadjuvant therapy } & $\begin{array}{c}\text { HR-positive } \\
\text { HER-2 negative }\end{array}$ & 4 & 10 & 8 & 6 \\
\hline & HER-2 positive & 2 & 3 & 3 & 3 \\
\hline & Triple-negative & 1 & 2 & 1 & 2 \\
\hline \multirow{3}{*}{ Metastatic } & $\begin{array}{c}\text { HR-positive } \\
\text { HER-2 negative }\end{array}$ & 7 & 7 & 4 & 5 \\
\hline & HER-2 positive & 2 & 2 & 1 & 1 \\
\hline & Triple-negative & 2 & 0 & 1 & 0 \\
\hline
\end{tabular}

chemotherapy or surgery (4-7). A study from China has shown that rate of SARS-CoV-2 infection in patients with cancer is $0.79 \%$ at their institution (8). Another Chinese study reported a mortality rate of $7.6 \%$ in all cancer patients (9). The need for intensive care, invasive ventilation, and mortality rates are slightly higher in patients with cancer than in individuals without cancer (hazard ratio: 2.293.50) (10). At our breast center, only six patients had COVID-19 infection in March and April 2020, and all were follow-up patients with early breast cancer. Two of them were living in another city. None of them required intensive care, and no deaths were due to COVID-19 infection.

Many patients avoid hospital visits to decrease their risk of exposure. In addition, many patients could not attend necessary medical visits because of local restrictions by government (such as curfew for people $>65$ years old). Chemotherapies were delayed or substituted by oral regimens for some patients during the early pandemic. All these changes decreased the number of hospital outpatient visits.

This study found that the presentation patterns of new breast cancer cases right after the early COVID-19 peak differed from those during the same period in the last 3 years. Data covering only two months of 2017-2020 were analyzed. Therefore, the number of new patients was low and did not allow us to make statistical comparisons between years. Despite the low number of new patients, our findings have shown that follow-up patients with breast cancer or women with undiagnosed breast tumors were terrified and did not visit hospitals right after the peak. A small proportion of new consultations (three, two, and two patients in 2017, 2018, and 2019, respectively) were ductal carcinoma in situ or lobular carcinoma in situ in the last 3 years, and no patients were consulted with a non-invasive histology in May and June 2020. Non-invasive disease was considered low priority during the pandemic. Therefore, all diagnostic and therapeutic procedures were postponed for these cases. Our findings revealed that oncologists preferred endocrine therapy more than chemotherapy in May/June 2020 irrespective of the disease stage.

Its retrospective nature and the small number of patients are the main still increasing following the early peak in April in Turkey and globally (1). Analyzing the patient presentation patterns of patients until the pandemic could be more informative because many patients avoid hospital visits with the fear of COVID-19 infection. Hence, the number of patients with local relapse and metastatic presentations may increase in the upcoming months.

\section{Acknowledgements}

We thank Aslınur Moral and Beren Büyükçolak for their valuable contributions in preparing the database for this retrospective study.

Ethics Committee Approval: This cross-sectional retrospective study was approved by the institutional review board at Altunizade Acibadem Hospital (no: 755 , date: 01.09 .2020 ).

Consent to participate: It is a retrospective study.

Peer-review: Externally peer-reviewed.

\section{Author Contributions}

Conception: A.D.I., C.D., A.S., N.G., E.Y., G.B.; Design: A.D.I., C.D., A.S., N.G., E.Y., G.B.; Data Collection and/or Processing: C.D.; Analysis and/ or Interpretation: A.D.I.; Literature Review: C.D.; Writing: G.B.; Critical Review: A.S., N.G., E.Y.

Conflict of Interest: There is no conflict of interest.

Financial Disclosure: The authors declared that this study received no financial support.

\section{References}

1. Available from: https://www.cdc.gov/coronavirus/2019-ncov/healthcarefacilities/guidance-hcf.html [Crossref]

2. Ontario Health, Cancer Care Ontario, "Pandemic Planning Clinical Guideline for Patients with Cancer". Last Accessed Date: 23.03.2020. Available from: https://www.accc-cancer. org/docs/document/cancerprogram-fundamentals/oh-ccopan-demicplanning-clinical-guidelines [Crossref] 


\section{Dauti Işıklar et al. COVID-19 and Breast Cancer}

3. Worldometer. COVID-19 Coronavirus Pandemic. Last Accessed Date: 12.09.2020. Available from: https://www.worldometers.info/coronavirus [Crossref]

4. Kamboj M, Sepkowitz KA. Nosocomial infections in patients with cancer. Lancet Oncol 2009; 10: 589-597. (PMID: 19482247) [Crossref]

5. Li JY, Duan XF, Wang LP, Xu YJ, Huang L, Zhang TF, et al. Selective depletion of regulatory $\mathrm{T}$ cell subsets by docetaxel treatment in patients with non-small cell lung cancer. J Immunol Res 2014; 2014: 286170. doi: 10.1155/2014/286170 (PMID: 24868562) [Crossref]

6. Longbottom ER, Torrance HD, Owen HC, Fragkou PC, Hinds CJ, Pearse RM, et al. Features of postoperative immune suppression are reversible with interferon gamma and independent of interleukin-6 pathways. Ann Surg 2016; 264: 370-377. (PMID: 26445474) [Crossref]
7. Sica A, Massarotti M. Myeloid suppressor cells in cancer and autoimmunity. J Autoimmun 2017; 85: 117-125. (PMID: 28728794) [Crossref]

8. Yu J, Ouyang W, Chua MLK, Xie C. SARS-CoV-2 Transmission in patients with cancer at a tertiary care hospital in Wuhan, China. JAMA Oncol 2020; 6: 1108-1110. (PMID: 32211820) [Crossref]

9. Report of the WHO-China Joint Mission on Coronavirus Disease 2019 (COVID-19) Available from: https://www.who.int/docs/default-source/ coronaviruse/who-china-joint-mission-on-covid-19-final-report.pdf [Crossref]

10. Guan W-J, Liang W-H, Zhao Y, Liang H-R, Chen Z-S, Li Y-M, et al. Comorbidity and its impact on 1590 patients with covid-19 in China: a nationwide analysis. Eur Respir J 2020; 55: 2000547.doi: 10.1183/13993003.00547-2020 (PMID: 32217650) [Crossref] 